\title{
A framework for clinical reasoning in adult cardiology
}

This article was published in the following Dove Press journal:

Advances in Medical Education and Practice

16 July 2015

Number of times this article has been viewed

\section{Carlos S de la Calzada}

Department of Medicine, Universidad Complutense de Madrid, Madrid, Spain
Correspondence: Carlos S de la Calzada Department of Medicine, Universidad Complutense de Madrid,Avda de Séneca, 2, Ciudad Universitaria, 28040 Madrid, Spain

Email cscalzada@hotmail.es
Abstract: It is well known that an expert clinician formulates a diagnostic hypothesis with little clinical data. In comparison, students have difficulties in doing so. The mental mechanism of diagnostic reasoning is almost unconscious and therefore difficult to teach. The purpose of this essay (devoted to 2nd-year medical students) is to present an integrating framework to teach clinical reasoning in cardiology. By analyzing cardiology with a synthetic mind, it becomes apparent that although there are many diseases, the heart, as an organ, reacts to illness with only six basic responses. The clinical manifestations of heart diseases are the direct consequence of these cardiac responses. Considering the six cardiac responses framework, diagnostic reasoning is done in three overlapping steps. With the presented framework, the process of reasoning becomes more visual and needs less clinical data, resembling that of the expert clinician.

Keywords: clinical deduction, diagnostic reasoning, education, teaching methods

\section{Introduction}

The purpose of medicine is to make a diagnosis and, afterward, consider prognosis and treatment. The most difficult task for students is diagnostic reasoning and to elaborate a diagnostic hypothesis. In essence, the abundant published literature devoted to diagnostic reasoning states that a careful analysis of symptoms and signs will generate the diagnosis and that the elaboration of a diagnostic hypothesis has to consider the suitable relationship between each clinical datum. ${ }^{1-6}$ According to me, most of these publications are philosophic essays for educators with little utility for beginners. Some authors have proposed more concrete approaches to teach clinical reasoning based on key features, but no clear explanation is offered about how to select the key features in the everyday practice. ${ }^{7}$

It is well known that an expert clinician formulates a diagnostic hypothesis with little clinical data; in comparison, most students have difficulties in doing so even with all of the patient's data. What is the integrating mental process of the expert clinician in formulating a diagnostic hypothesis with little data, and in addition, how does one teach it? The problem is that the mental mechanism of diagnostic reasoning is almost unconscious and therefore difficult to teach. Perhaps this is why synthesis and diagnostic reasoning is rarely taught in medical schools. ${ }^{8}$ To start diagnostic reasoning, it is mandatory to select some basic clinical data and then to proceed with the specific process of deduction. In this regard, what students need is a constant framework or preexisting structure to easily identify the key features and to integrate them in the process of reasoning. Therefore, the purpose of this essay (devoted to 2 nd-year medical students) is to present an integrating framework and to explain how to use it to teach 
clinical reasoning in general adult cardiology. Congenital heart diseases are excluded from this analysis.

\section{The difficulty of diagnostic reasoning}

The difficulty of diagnostic reasoning for beginners may be related to the following reasons:

First, cardiology consists of many different diseases but few clinical manifestations. In fact, there are only five main symptoms (dyspnea, edema, angina/chest pain, palpitations/ tachycardia, and syncope/sudden death) that are shared by most cardiac diseases and even with noncardiac diseases. On the other hand, except for some specific heart murmurs and pericardial rub or knock (that directly gives the diagnosis), most of the physical signs are also nonspecific (jugular venous pressure, carotid pulse, gallops, pulmonary rales, ankle edema, etc). Finally, the most common ECG pathologic patterns (ventricular hypertrophy, bundle branch blocks, Q-waves, and certain ST-T abnormalities) can be shared by various diseases.

Second, most textbooks are structured in isolated chapters about different diseases. Therefore, students tend to learn cardiology by remembering each disease separately, making the process of diagnostic deduction difficult.

\section{The six basic cardiac responses to illness: the substratum for clinical integration and diagnostic reasoning}

Integration is the process of bringing different parts together into a whole. ${ }^{9}$ That is to say, giving a common interpretation to the various clinical manifestations. By analyzing cardiology with a synthetic and integrating mind, it becomes apparent that although there are many diseases, the heart, as an organ, reacts to illness with only six basic responses:

1. Ventricular hypertrophy: left/right.

2. Chamber dilatation: ventricle/atrium.

3. Valve dysfunction: primary pathology or secondary dysfunction.

4. Myocardial ischemia: primary or secondary.

5. Rhythm and block disorders: primary or secondary.

6. Pulmonary hypertension (especially group 2 type of its classification). ${ }^{10}$

It is important to notice that one or more of these responses are always present in any adult cardiac disease, because they are the pathophysiological substrate of most clinical manifestations of cardiology, as shown later. Each cardiac response is also the substrate of many physical signs as shown in Table 1. The most important ECG patterns are due to responses 1, 2, 4, and 5 (Table 1). Finally, echocardiography (not considered in this essay) accurately evaluates all cardiac responses except number 5 . That is why echocardiography is so useful for diagnosis although so detrimental for clinical reasoning and learning physical examination.

At this point, it is vital to remark that the major clinical manifestations of heart diseases are the direct consequence of these cardiac responses. This is why the many and different cardiac diseases have so few and nonspecific clinical manifestations. This concept is crucial to the teaching of the process of diagnostic reasoning.

\section{The process of diagnostic reasoning}

Considering the six cardiac responses, diagnostic reasoning may be facilitated if it is done in three overlapping steps.

\section{First step: diagnosis of the basic cardiac responses present in the patient}

Students must initially place emphasis only on the diagnosis of the cardiac responses. They must develop agility in identifying these cardiac responses, which is relatively easy using physical examination, ECG, and chest X-ray, as shown in Table 1.

\section{Second step: check the probable diseases that share the cardiac responses present in the patient}

Once cardiac responses are defined, it is possible to elaborate a diagnostic hypothesis and differential diagnosis from among the diseases that share those responses following Table 2. With this approach, differential diagnosis becomes a logical strategy based on similarities and not a list of unconnected diseases one has to memorize.

Third step: the final diagnostic construction of the specific disease

The construction of left and right heart diseases are analyzed separately.

\section{Diagnostic construction of left heart diseases}

The diagnosis of left heart diseases is based on two elements: 1) the state of the left ventricle (normal, hypertrophic, 
Table I Clinical features of the six basic cardiac responses

\begin{tabular}{|c|c|c|c|}
\hline Cardiac responses & Physical signs & ECG & Chest X-ray \\
\hline $\begin{array}{l}\text { Left ventricular } \\
\text { hypertrophy }\end{array}$ & Sustained ventricular impulse, S4 & LVH or LBBB & $\begin{array}{l}\text { Prominent LV (PA } \\
\text { projection X-ray) }\end{array}$ \\
\hline $\begin{array}{l}\text { Right ventricular } \\
\text { hypertrophy }\end{array}$ & $\begin{array}{l}\text { Impulse not felt in adults } \\
\text { Right S4 }\end{array}$ & $\mathrm{RVH} / \mathrm{RBBB}$ Right axis deviation & $\begin{array}{l}\text { Prominent RV (lateral } \\
\text { projection X-ray) }\end{array}$ \\
\hline $\begin{array}{l}\text { Left ventricular } \\
\text { dilatation }\end{array}$ & $\begin{array}{l}\text { Displaced LV impulse } \\
\text { S3, M Reg murmur? }\end{array}$ & LVH, old infarct pattern, LBBB & $\begin{array}{l}\text { Prominent LV (PA } \\
\text { projection X-ray) }\end{array}$ \\
\hline RV dilatation & $\begin{array}{l}\text { Impulse not felt } \\
\text { Right S3 } \\
\text { TR Reg murmur? }\end{array}$ & $\mathrm{RVH} / \mathrm{RBBB}$ & $\begin{array}{l}\text { Prominent RV (lateral } \\
\text { projection X-ray) }\end{array}$ \\
\hline Atrial dilatation & None & Prominent $\mathrm{P}$-waves or $\mathrm{AF}$ & Prominent atria \\
\hline $\begin{array}{l}\text { Aortic valve } \\
\text { dysfunction }\end{array}$ & $\begin{array}{l}\text { AoSt: Syst murmur, anacrotic pulse } \\
\text { AoReg: Diast murmur, brisk pulse }\end{array}$ & LVH/LBBB & $\begin{array}{l}\text { Prominent } \mathrm{LV} \text { and } \\
\text { ascending aorta }\end{array}$ \\
\hline $\begin{array}{l}\text { Mitral valve } \\
\text { dysfunction }\end{array}$ & $\begin{array}{l}\text { M Reg: Syst murmur } \\
\text { MSten: Diast murmur, opening snap }\end{array}$ & LVH (M Reg) FA (MSten) & $\begin{array}{l}\text { M Reg: prominent LV } \\
\text { MSten: prominent LA }\end{array}$ \\
\hline $\begin{array}{l}\text { Tricuspid valve } \\
\text { dysfunction }\end{array}$ & $\begin{array}{l}\text { TR Reg: JVP: V-wave, Syst murmur } \\
\text { (> inspiration) TR Sten: JVP: A-wave }\end{array}$ & Prominent $\mathrm{P}$-waves or $\mathrm{AF}$ & Prominent RA \\
\hline $\begin{array}{l}\text { Pulmonary } \\
\text { Hypertension }\end{array}$ & $\begin{array}{l}\text { Loud P2, JVP }>3 \mathrm{~cm} \text { TR Reg } \\
\text { ( }>\text { inspiration) } \mathrm{S} 4, \mathrm{~S} 3(>\text { inspiration) }\end{array}$ & RVH, RBBB & $\begin{array}{l}\text { Prominent RV, RA, } \\
\text { and main pulmonary } \\
\text { arteries }\end{array}$ \\
\hline Myocardial ischemia & S4, S3, M Reg murmur & Abnormal ST-T, Q-waves, and VT & None specific \\
\hline Arrhythmias & Certain arterial pulse abnormalities & Specific patterns & None \\
\hline
\end{tabular}

Notes: $>$ is increased and ? is possible.

Abbreviations: AF, atrial fibrilation; AoReg, aortic regurgitation; AoSt, aortic stenosis; Diast, diastolic; JVP, jugular venous pulse; LA, left atrium; LBBB, left bundle branch block; LV, left ventricle; LVH, left ventricular hypertrophy; M Reg, mitral regurgitation; MSten, mitral stenosis; P2, second heart sound; PA, pulmonary artery; RA, right atrium; RBBB, right bundle branch block; RV, right ventricle; RVH, right ventricular hypertrophy; S3, third heart sound; S4, fourth heart sound; Syst, systolic; TR, tricuspide; VT, ventricular tachycardia.

or dilated); and 2) presence or absence of murmurs. Combining these two elements, the following three diagnostic groups can be made.

\section{Group A: heart diseases with left ventricular hypertrophy}

Left ventricular hypertrophy is easy to diagnose with ECG, and the three main heart diseases with left ventricular hypertrophy are:

1. Arterial hypertension: no murmurs except in the elderly were aortic sclerosis or stenosis may coexist.

2. Aortic stenosis: evident and typical ejection murmur.

3. Hypertrophic cardiomyopathy: typical murmur only in obstructive type.

They all share many clinical features related to left ventricular hypertrophy (palpable ventricle, fourth heart sound, and possible systolic murmur), symptoms (dyspnea, angina, syncope), and possible atrial fibrillation or ventricular arrhythmias. Additional features such as blood pressure, carotid pulse morphology, and murmur characteristics will give the final diagnosis. Also, it is easy to understand for students that the diagnostic hypothesis of dyspnea, angina, or syncope with or without left ventricular hypertrophy is different, and if heart failure occurs with left ventricular hypertrophy it is almost always with preserved ejection fraction. With this approach, the student begins to understand the basis of differential diagnosis.

\section{Group B: heart diseases with left ventricular dilatation}

The main heart diseases producing left ventricular dilatation are:

1. Coronary artery disease: ischemic dilated cardiomyopathy or large old myocardial infarct (possible secondary mitral regurgitant murmur).

2. Nonischemic dilated cardiomyopathy (possible secondary mitral regurgitant murmur).

3. Chronic primary mitral regurgitation (evident regurgitant murmur).

4. Chronic aortic regurgitation. (specific diastolic murmur). They all share the features of chronic left ventricular dilatation (similar X-ray appearance, palpable ventricle, third heart sound) apart from the murmurs previously mentioned. In contrast to hypertrophy (with well-defined ECG pattern), there is no specific ECG pattern of left ventricular 
Table 2 Construction of heart diseases with the basic cardiac responses and type of probable heart failure

\begin{tabular}{|c|c|c|c|c|c|c|c|}
\hline & VENT HYPER & VENT DILAT & VALVE DYSFUN & PULM HYPERT & ARRHYTHM & MYOCAR ISCHEM & HF \\
\hline $\begin{array}{l}\text { Hypertrophic } \\
\text { cardiomyopathy }\end{array}$ & $\begin{array}{l}\text { Yes +++ } \\
\text { S4 }\end{array}$ & No & $\begin{array}{l}\text { Syst Mur if } \\
\text { obstructive }\end{array}$ & No & $\begin{array}{l}\text { Syncope VT/ } \\
\text { AF }\end{array}$ & $\begin{array}{l}\text { Possible } \\
\text { angina }\end{array}$ & $\begin{array}{l}\text { Yes } \\
\text { (HFpEF) }\end{array}$ \\
\hline $\begin{array}{l}\text { Dilated } \\
\text { cardiomyopathy }\end{array}$ & No & $\begin{array}{l}\text { Yes S3 } \\
+++\end{array}$ & Mitral Reg & $\begin{array}{l}\text { Possible } \\
++\end{array}$ & $\mathrm{VT} / \mathrm{AF}$ & $\begin{array}{l}\text { Possible } \\
\text { angina }\end{array}$ & $\begin{array}{l}\text { Yes } \\
\text { (HFrEF) }\end{array}$ \\
\hline $\begin{array}{l}\text { Restrictive } \\
\text { cardiomyopathy }\end{array}$ & $\begin{array}{l}+1-\text { S3- } \\
\text { S4 }\end{array}$ & No & $\begin{array}{l}\text { Mitral/Tr } \\
\text { Reg }\end{array}$ & $\begin{array}{l}\text { Possible } \\
++\end{array}$ & $\mathrm{AF} / \mathrm{VT}$ & $\begin{array}{l}\text { Possible } \\
\text { angina }\end{array}$ & $\begin{array}{l}\text { Yes } \\
\text { (HRpEF) }\end{array}$ \\
\hline $\begin{array}{l}\text { Arterial } \\
\text { hypertension }\end{array}$ & $\begin{array}{l}\text { Yes ++ } \\
\text { S4 }\end{array}$ & $\begin{array}{l}\text { Possible } \\
+\end{array}$ & No & No & $\mathrm{AF} / \mathrm{VT}$ & $\begin{array}{l}\text { Possible } \\
\text { angina }\end{array}$ & $\begin{array}{l}\text { Yes } \\
\text { (HFpEF) }\end{array}$ \\
\hline Aortic stenosis & $\begin{array}{l}\text { Yes +++ } \\
\text { S4 }\end{array}$ & $\begin{array}{l}\text { Possible } \\
+\end{array}$ & $\begin{array}{l}\text { Syst Mur } \\
\text { Anacrotic } \\
\text { pulse }\end{array}$ & $\begin{array}{l}\text { Possible } \\
++\end{array}$ & $\mathrm{AF} / \mathrm{VT}$ & $\begin{array}{l}\text { Possible } \\
\text { angina }\end{array}$ & $\begin{array}{l}\text { Yes } \\
\text { (HFpEF) }\end{array}$ \\
\hline $\begin{array}{l}\text { Aortic } \\
\text { regurgitation }\end{array}$ & Yes + & $\begin{array}{l}\text { Yes +++ } \\
\text { S3 }\end{array}$ & $\begin{array}{l}\text { Diast Mur } \\
\text { Brisk pulse }\end{array}$ & Possible + & No & No & $\begin{array}{l}\text { Yes } \\
\text { (HFrEF) }\end{array}$ \\
\hline $\begin{array}{l}\text { Mitral } \\
\text { regurgitation }\end{array}$ & Yes ++ & $\begin{array}{l}\text { Yes +++ } \\
\text { S3 }\end{array}$ & Syst Mur & Possible ++ & $\mathrm{AF} / \mathrm{VT}$ & No & $\begin{array}{l}\text { Yes } \\
\text { (HFrEF) }\end{array}$ \\
\hline $\begin{array}{l}\text { Mitral } \\
\text { stenosis }\end{array}$ & No & $\begin{array}{l}\text { No, Atrial } \\
\text { Dilat }\end{array}$ & $\begin{array}{l}\text { Loud SI } \\
\text { Diast Mur } \\
\text { Op snap }\end{array}$ & $\begin{array}{l}\text { Possible } \\
++++\end{array}$ & AF embolism & No & $\begin{array}{l}\text { Yes } \\
\text { (HFpEF) }\end{array}$ \\
\hline $\begin{array}{l}\text { Tricuspid } \\
\text { regurgitation }\end{array}$ & $\mathrm{RVH}+$ & $\begin{array}{l}\text { Yes +++ } \\
\text { S3 }\end{array}$ & $\begin{array}{l}\text { Syst Mur } \\
\text { >inspiration }\end{array}$ & No & $\mathrm{AF}$ & No & $\begin{array}{l}\text { >JVP } \\
\text { (V-wave) }\end{array}$ \\
\hline $\begin{array}{l}\text { Coronary } \\
\text { disease without } \\
\text { infarction }\end{array}$ & No & No & $\begin{array}{l}\text { No } \\
\text { S4 }\end{array}$ & No & VT? & Angina & No \\
\hline $\begin{array}{l}\text { Coronary } \\
\text { disease with } \\
\text { infarction }\end{array}$ & No & Yes +++ & $\begin{array}{l}\text { Mitral Reg? } \\
\text { S4-S3 }\end{array}$ & Possible ++ & VT & Yes angina & $\begin{array}{l}\text { No/yes } \\
\text { (HFrEF) }\end{array}$ \\
\hline $\begin{array}{l}\text { Lone atrial } \\
\text { fibrillation }\end{array}$ & No & No & No & No & Embolism AF & $\begin{array}{l}\text { Possible } \\
\text { angina }\end{array}$ & $\begin{array}{l}\text { No/yes } \\
\text { (HFpEF) }\end{array}$ \\
\hline $\begin{array}{l}\text { Supraventricular } \\
\text { tachycardia }\end{array}$ & No & No & No & No & SVT syncope & $\begin{array}{l}\text { Possible } \\
\text { angina }\end{array}$ & No \\
\hline $\begin{array}{l}\text { Bradyarrhythmia } \\
\text { AV block }\end{array}$ & No & Possible & No & No & Syncope & No & No \\
\hline $\begin{array}{l}\text { Acute } \\
\text { pericarditis }\end{array}$ & No & No & No, rub & No & No & $\begin{array}{l}\text { Pericardial } \\
\text { pain }\end{array}$ & No \\
\hline $\begin{array}{l}\text { Constriction } \\
\text { tamponade }\end{array}$ & No & No & $\begin{array}{l}\text { No, } \\
\text { knock, rub }\end{array}$ & No & No & No & $\begin{array}{l}\text { >JVP, } \\
\text { right } \mathrm{HF}\end{array}$ \\
\hline PULM HYPERT & $\mathrm{RVH}+$ & RVD ++ & $\begin{array}{l}\text { Tricuspid } \\
\text { Reg }\end{array}$ & Yes P2 ++ & $\begin{array}{l}\text { Syncope VT } \\
\text { SVT }\end{array}$ & Angina? & $\begin{array}{l}\text { >JVP, } \\
\text { right HF }\end{array}$ \\
\hline
\end{tabular}

Notes: $>$ is increased; ? is possible; - is absence; and + is presence (the number of + indicates the severity).

Abbreviations: AF, atrial fibrillation; ARRHYTHM, arrhythmias; Diast, diastolic; HF, heart failure; HFpEF, heart failure with preserved ejection fraction; HFrEF, heart failure with reduced ejection fraction; JVP, jugular venous pulse; Mur, murmur; MYOCAR ISCHEM, myocardial ischemia; Op, opening snap; PULM HYPERT, pulmonary hypertension; Reg, regurgitation; RVD, right ventricular dilatation; RVH, right ventricular hypertrophy; SI, first heart sound; S3, third heart sound; S4, fourth heart sound; SVT, supraventricular tachycardia; Syst, systolic; Tr, tricuspide; VALVE DYSFUN, valve dysfunction; VENT DILAT, ventricular dilatation; VENT HYPER, ventricular hypertrophy; VT, ventricular tachycardia.

dilatation. Nevertheless, considering the abovementioned cardiac diseases producing left ventricular dilatation, the ECG patterns associated to them are: left ventricular hypertrophy, left bundle branch block, and old anterior myocardial infarction.

Considering this approach, the frequent differential diagnosis between primary chronic mitral regurgitation, ischemic dilated cardiomyopathy, and nonischemic dilated cardiomyopathy, both with and without secondary mitral regurgitation, are easily appreciated by the student. Evidently, heart failure in this group of diseases is of systolic type (left ventricular dilatation and low ejection fraction).

\section{Group C: heart diseases with "normal” left ventricle}

In this group, the left ventricle is considered "normal" for teaching purposes because it is neither hypertrophic nor dilated. The most frequent diagnostic possibilities in this group are:

1. Coronary artery disease without previous infarction or small infarct (no murmurs). 
2. Isolated atrial fibrillation (no murmurs).

3. Different forms of supraventricular tachycardia (no murmurs).

4. Mitral stenosis (specific auscultatory features).

In all these examples, if heart failure occurs, it is usually with normal ejection fraction.

\section{Diagnostic construction of right heart diseases}

The diagnosis of right heart diseases is based on three elements:

1. State of the right ventricle: normal or hypertrophic/ dilated. In the right ventricle there is not always a clear limit between hypertrophy and dilatation; that is why the right ventricle is considered as normal or a combination of hypertrophy and dilated (see Table 1 for the basic signs of right ventricular hypertrophy or dilatation).

2. Presence or absence of pulmonary hypertension. See Table 1 for the main diagnostic features of pulmonary hypertension.

3. Presence or absence of right heart murmurs.

With these three elements the following diagnostic groups may be obtained.

\section{Group A: hypertrophic/dilated right ventricle with pulmonary hypertension and possible murmurs}

The more frequent cardiac conditions of this group are:

1. Chronic left heart diseases with secondary pulmonary hypertension (group 2 of pulmonary hypertension classification ${ }^{10}$ ). This is by far the most frequent cause of pulmonary hypertension and right ventricular failure in everyday practice.

2. Cor pulmonale. Identified by signs of pulmonary hypertension and pulmonary disease.

3. Adult atrial septal defect. Identified with specific murmurs and ECG.

\section{Group B: hypertrophic/dilated} right ventricle without pulmonary

\section{hypertension and possible murmurs}

This group is rare but the cardiac conditions to consider are:

1. Pulmonary valve stenosis. Identified by murmur and ECG.

2. Right ventricular involvement of myocardial infarction (rare condition).

3. Isolated tricuspid regurgitation, and right ventricular cardiomyopathies (all very rare).
Group C: normal right ventricle, obviously without pulmonary hypertension and with possible murmurs

The right ventricle is normal because there are no features of hypertrophy/dilatation. In other words, the QRS is normal. The more frequent cardiac conditions of this group are:

1. Pericardial constriction or tamponade (increased jugular venous pulse, clear lungs, no murmurs and possible rub or knock).

2. Isolated Tricuspid stenosis (specific murmur).

The common clinical manifestation of groups A, B, and C is heart failure. In group A, heart failure is usually both right and left. In groups B and C, heart failure is pure right with clear lungs. Apart from acute pericarditis, pericardial diseases are basically manifested by elevated jugular venous pulse, possible peripheral edema, and clear lung fields with normal ventricles and valves. The ECG is almost "normal" apart from low voltage and possible atrial fibrillation if there is atrial dilatation.

The construction of left and right heart diseases are represented in Figures 1 and 2 for teaching purposes.

\section{Other uses of the six cardiac responses framework: teaching integration of knowledge}

As previously mentioned, teaching is traditionally organized in isolated or compartmentalized diseases making the integration of knowledge very difficult.

One way to improve integration of clinical knowledge is to change the traditional order of teaching the various diseases and to do so following the grouping set out in the

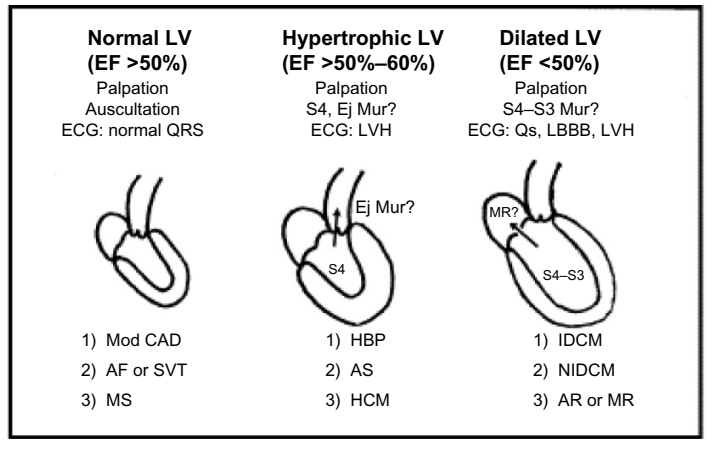

Figure I Diagnostic construction of left heart diseases.

Note: ? is possible.

Abbreviations: $A F$, atrial fibrillation; $A R$, aortic regurgitation; $A S$, aortic stenosis; $E F$, ejection fraction; Ej Mur, ejection murmur; HBP, high blood pressure; HCM, hypertrophic cardiomyopathy; IDCM, ischemic dilated cardiomyopathy; LBBB, left bundle branch block; LV, left ventricle; LVH, left ventricular hypertrophy; Mod CAD, moderate coronary artery diseases (without infarction or small); $M R$, mitral regurgitation; MS, mitral stenosis; Mur, murmur; NIDCM, nonischemic dilated cardiomyopathy; S3, ventricular gallop; S4, atrial gallop; SVT, supraventricular tachycardia. 


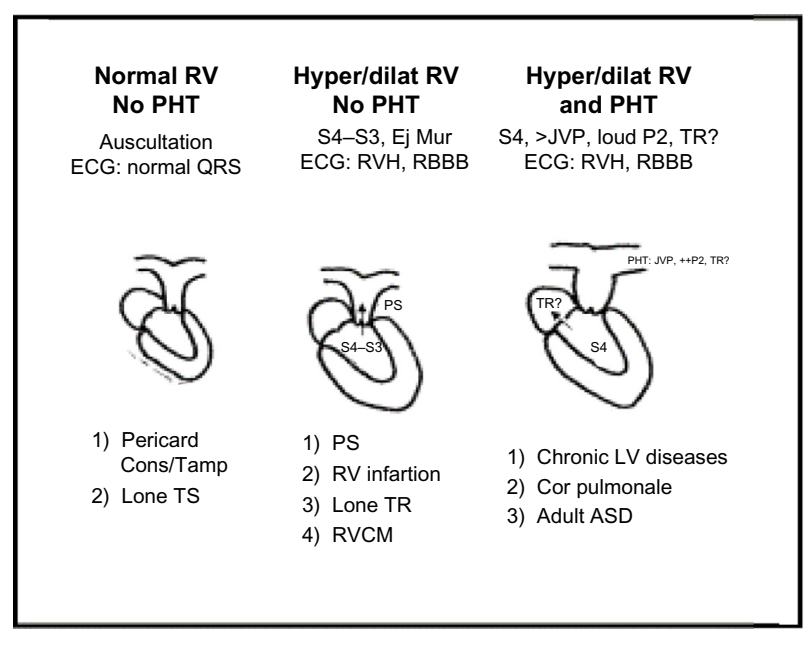

Figure 2 Diagnostic construction of right heart diseases.

Notes: $>$ is increased; ? is possible; and + is presence (the number of + indicates the severity).

Abbreviations: ASD, atrial septal defect; Ej Mur, ejection murmur; Hyper/dilat, hypertrophic/dilated; JVP, jugular venous pulse; P2, pulmonary second heart sound; Pericard Cons/Tamp, pericardial constriction/tamponade; $\mathrm{PHT}$, pulmonary hypertension; PS, pulmonary stenosis; RBBB, right bundle branch block; RV, right ventricle; RVCM, right ventricular cardiomyopathy; RVH, right ventricular hypertrophy; S3, ventricular gallop; S4, atrial gallop; TR, tricuspid regurgitation; TS, tricuspid stenosis.

section on construction of left and right heart diseases. Such grouping facilitates integration of knowledge and diagnostic reasoning. Also, various clinical data of a patient which may appear to be different (physical signs, ECG, X-ray, 2D-echocardiography, and other diagnostic imaging techniques), may have a common interpretation based on the six cardiac responses model.

Another approach to teaching the integration of knowledge is to invent a new clinical scenario to promote the diagnosis of the clinical state of each cardiac structure. That is, to analyze the physical signs, ECG, and X-ray findings generated by each structure: myocardium, valves, coronary tree, conductive system, and pericardium. Knowing which heart structure is primarily affected, which is secondarily involved, and which is normal facilitates integration and diagnostic skills.

\section{The approach to physical examination}

Again, text books are organized in a disintegrating order jugular venous pulse, arterial pulses, classification of murmurs, clicks, rub, etc - and each physical sign has a long list of causes to memorize. With such presentation, it is very difficult to see physical examination as a diagnostic tool. A frequent problem for new students while examining a patient is that they do not know what to look for or how to integrate the findings with other clinical data. The goal of physical examination, as with any other diagnostic method, is to define the various cardiac responses according to their particular physical signs (see Table 1). The approach of physical examination through the six cardiac responses and heart structures offers a plan of action and a comprehensive view of it.

\section{The approach to the ECG clinical interpretation}

There are many good ECG textbooks describing in detail the diagnostic criteria of all the ECG abnormalities, but their clinical interpretation/integration is rarely considered. One way to enlighten the clinical interpretation is to consider the possible ECG patterns of each cardiac response. As mentioned before, the most important ECG patterns are due to responses 1, 2, 4, and 5. The P-wave, atrial fibrillation, or flutter reflects the state of the atrium and the QRS the state of the myocardium. The ST-T segment reflects ischemia or inflammation of the pericardium as the most frequent causes. Finally, a tachyarrhythmia without any other cardiac response is indicative of a primary "electric" disease.

\section{The approach to the interpretation of cardiac imaging diagnostic techniques}

In essence, the various imaging techniques only examine the six cardiac responses; therefore, the same model may be used to teach the basic diagnostic approach of these diagnostic techniques.

\section{Connection of basic science and clinical practice}

A suitable background in basic sciences facilitates the understanding of many aspects of clinical medicine. Nevertheless, this is seldom appreciated by a 2nd-year student, probably because basic sciences are taught distant in time from the clinical practice. By teaching the basic sciences of each cardiac response, the distance from bench to bedside is reduced.

\section{Conclusion}

The presented six cardiac response model is a concrete and constant preexisting structure that facilitates the following aspects of clinical teaching:

1. The process of reasoning becomes more visual and needs less clinical data, resembling that of the expert clinician.

2. It gives a simple structure to integrate all diagnostic data. The apparent dispersion of physical signs, ECG, chest $\mathrm{X}$-ray findings, and other diagnostic images techniques can be integrated into a common mental interpretation.

3. It facilitates the relation between basic science and clinical knowledge. 
The model is simple (virtues and defects) but it is useful for the first steps of diagnostic reasoning. Furthermore, each student can modify it.

\section{Disclosure}

The author reports no conflicts of interest in this work.

\section{References}

1. Eva KW. What every teacher needs to know about clinical reasoning. Med Educ. 2005;39:98-106.

2. Irby DM. What clinical teachers in medicine need to know. Acad Med. 1994;69:333-342.

3. Elstein AS, Schwarz A. Clinical problem solving and diagnostic decision making: Selective review of the cognitive literature. $B M J$. 2002;324:729-732.
4. Goss JR. Teaching clinical reasoning to second-year medical students. Acad Med. 1996;71:349-352.

5. Durning S, Artino AR Jr, Pangaro L, van der Vleuten CP, Schuwirth L. Context and clinical reasoning: understanding the perspective of the expert's voice. Med Educ. 2011;45:927-938.

6. Bowen JL. Educational strategies to promote clinical diagnostic reasoning. N Engl J Med. 2006;355:2217-2225.

7. Farmer EA, Page G. A practical guide to assessing clinical decisionmaking skills using the key features approach. Med Educ. 2005;39: $1188-1194$.

8. Mookherjee S, Chou CL. Bedside teaching of clinical reasoning and evidence-based physical examination. Med Educ. 2011;45:519.

9. Guralnik DB, editor. Webster's New World Dictionary: Pocket size edition. 1984. ISBN o-446-31299-1.

10. Simonneau G, Gatzoulis MA, Adatia I, et al. Updated clinical classification of pulmonary hypertension. $J$ Am Coll Cardiol. 2013; 62(25 Suppl):D34-D41.

\section{Publish your work in this journal}

Advances in Medical Education and Practice is an international, peerreviewed, open access journal that aims to present and publish research on Medical Education covering medical, dental, nursing and allied health care professional education. The journal covers undergraduate education, postgraduate training and continuing medical education including emerging trends and innovative models linking education, research, and health care services. The manuscript management system is completely online and includes a very quick and fair peer-review system. Visit http://www.dovepress.com/testimonials.php to read real quotes from published authors.

Submit your manuscript here: http://www.dovepress.com/advances-in-medical-education-and-practice-journal 